\title{
Aspetos importantes do legado árabe na língua portuguesa
}

\section{Abdelilah Suisse}

Universidade de Aveiro

Centro de Línguas, Literaturas e Culturas

- asuisse@ua.pt

Dol https://doi.org/10.34913/

journals/lingualugar.2020.e418 
Durante o domínio muçulmano na Península Ibérica, no Al-Andalus e Gharb Al- Andalus, que teve lugar entre 711 e 1492, a língua árabe foi um relevante veículo de cultura e de ciência nessa região, tendo deixado um legado linguístico notável no português e no castelhano.

O presente artigo propõe-se descrever e analisar alguns aspetos importantes da influência árabe na língua portuguesa. $O$ estudo realizou-se partindo da seleção de um corpus composto por vinte arabismos pertencente a vários campos linguísticos.

O estudo concluiu que a influência da língua árabe no português está associada, sobretudo, à conservação do artigo definido, sob as formas lunar (ex. alface, alfazema, almoxarife) e solar (ex. adufe, açude, açúcar) que se aglutinam aos substantivos, atuando como prefixos. Através destes e doutros exemplos, verificou-se que os aprendentes de português (cuja língua materna é o árabe) acabam, na realidade, por empregar uma forma híbrida, usando dois artigos definidos - o do português [o/a(s)] e o do árabe [al] ou [a]. Quanto ao aspeto cultural, o trabalho apresenta e explica alguns exemplos de difusão cultural árabe-muçulmana na Península Ibérica em que os arabismos testemunham, verdadeiramente, essa aculturação que se manifesta amplamente na agricultura, nas artes e ciências, na arquitetura, entre muitos outros domínios.

Palavras-chave: Contacto linguístico; arabismos portugueses; árabes no Ghab Al-Andalus 
44 Pendant la domination musulmane sur la Péninsule lbérique, en Al-Andalus et Gharb Al-Andalus, qui a eu lieu entre 711 et 1492, la langue arabe était un vecteur important de culture et de science dans cette région. Elle a laissé, effectivement, un héritage linguistique remarquable aux langues ibériques.

A partir de ce constat, cet article a comme objectif de décrire et d'analyser certains aspects importants de l'influence arabe dans la langue portugaise. L'étude a été réalisée à partir de la sélection d'un corpus composé de vingt arabismes appartenant à plusieurs domaines linguistiques.

L'étude a conclu que l'influence linguistique des arabismes en portugais est surtout associée à la conservation des articles lunaires (ex: alface, alfazema, almoxarife) et solaires (ex. adufe, açude, açúcar) qui se joignent aux noms sous forme de préfixes. On a constaté, à travers ces exemples et d'autres, que les apprenants de portugais (dont la langue maternelle est l'arabe) finissent par utiliser une forme hybride, en utilisant deux articles le portugais [o/a(s)] et l'arabe [al] ou [a]. Ainsi, on pourrait dire que l'usage en double de l'article constitue la caractéristique la plus importante des arabismes affectant qui affectent le portugais. Sur le plan culturel, l'article présente et explique quelques exemples de la diffusion culturelle arabo-musulmane en Péninsule Ibérique où les arabismes témoignent véritablement de cette acculturation qui se manifeste largement dans l'agriculture, les arts et les sciences, en architecture, parmi bien d'autres domaines.

Mots-clés: Contact linguistique; arabismes portugais; arabes à Ghab Al-Andalus 
A Lingua Portugueza he principalmente composta das línguas, Latina, Grega e Arabica... e também ficamos conservando tantas palavras Arabicas, que dellas bem se póde compor hum arrazoado léxicon Fr. João de Sousa ([1789] 2004, p. 1).

Durante oito séculos (de 711 até 1492), o domínio muçulmano ${ }^{1}$ na Península Ibérica permitiu que a língua árabe representasse um importante veículo de cultura e de ciência nesta região, tendo deixado um legado linguístico notável nas línguas ibéricas. ${ }^{2}$ De facto, é de entendimento pacífico, entre os estudiosos, a importância da língua árabe como segunda fonte das línguas ibéricas (castelhano e português), sendo apenas ultrapassada pelo latim (Vasconcelos,1946; Sidarus, 2009). Esta ideia é reforçada pelo facto de, para alguns investigadores, o léxico de origem árabe ser considerado como hereditário e não um simples empréstimo (Machado Filho, 2013), porque encontramos muitos topónimos de origem árabe em várias regiões de Portugal (ex. Algarve, Albufeira, Aljezur, Alcácer, Azeitão, Algueirão, Cacém, Mafamude).

A consideração da importância da língua como veículo cultural é transversal a vários autores. A ideia da criação de uma comunidade que se ancora no vetor linguístico foi realçada pelo arabista espanhol Federico Corriente (2006) quando fala de uma Romania Arabica para se referir ao espaço linguístico-cultural compartilhado por comunidades falantes de línguas maternas diversas, onde se incluem quer as comunidades arabófonas e islâmicas, quer as neolatinas e cristãs, deixando transparecer, também, o legado árabe nas línguas neolatinas.

Assim, com este artigo, pretende-se identificar e analisar aspetos relevantes sobre as influências linguísticas e culturais da língua árabe presentes no português, tal como observamos, hoje em dia, em ambos os idiomas. Concretamente, abordamos não apenas aspetos dos arabismos da língua portuguesa relacionados com a integração ou não do artigo sob as formas solar ou lunar, ${ }^{\mathbf{3}}$ mas também as alterações fonéticas.

\footnotetext{
1 Neste artigo, usamos a referência religiosa muçulmano(os) que engloba a população árabe, berbere e persa.

2 2 Neste artigo, as línguas ibéricas remetem para o castelhano e para o português.

3

3 A origem desta designação tem a ver com o facto de "o sol", em árabe, alshams / آلََّّمس, ser pronunciado asshams, assimilando o I / J; enquanto "a lua", escreve-se e pronuncia-se alqamar / ألََْمَر. Por esta razão, "o sol" e "a lua" foram tomadas em árabe como referências pelos linguistas para distinguir dois tipos fonéticos de artigo definido. Como consequência desta distinção, na língua árabe encontramos, também, consoantes solares e lunares.
} 
Trata-se, pensamos, de questões pouco exploradas nos estudos realizados, até agora, sobre os arabismos, sobretudo no português, que se debruçaram mais sobre a análise etimológica dos mesmos (Lopes, 1949; Machado, 1997; Farinha, 1973; Sidarus, 1986, entre outros) e sobre a presença da sua presença nos textos literários (Suisse, 2004).

\section{Integração dos arabismos na língua portuguesa: perspetiva histórica}

Antes de apresentar uma visão histórica sobre a integração do legado linguístico árabe nas línguas românicas - especialmente no português, considera-se importante definir o termo arabismo(s). Pela sua importância nos contactos linguísticos, os arabismos têm sido objeto de muitas definições em vários dicionários que os caracterizam, genericamente, como sendo todo o tipo de herança árabe na Península Ibérica. O dicionário Houaiss define arabismo como uma «expressão/característica da língua árabe; palavra, construção ou expressão próprias da língua árabe numa outra língua». Para o Dicionário da Língua Espanhola, Real Academia (RAE), um arabismo refere-se a "Giro o modo de hablar propio de la lengua árabe; Vocablo o giro de la lengua árabe empleado en otra". Pelo seu lado, o Dictionnaire de Français Larousse introduz no conceito um elemento cultural, considerando-o uma "construction, expression propre à la langue arabe; particularité propre à la civilisation arabe". Estas definições são fruto de estudos científicos realizados sobre a influência do árabe nas línguas neolatinas que analisam temas de linguística e de cultura.

Em todas estas definições encontramos patente a ideia de coexistência que terá sido estabelecida entre cristãos e muçulmanos na Península Ibérica. Esta terá florescido durante o domínio árabe e muçulmano, embora a tarefa de delimitar os períodos temporais da entrada dos arabismos se afigure de complexa realização, de acordo com a literatura especializada sobre o tema. Esta dificuldade é devida ao facto de o contacto entre o árabe e as línguas ibéricas não ter tido lugar exclusivamente na Península Ibérica medieval, mas também, em períodos mais tardios, em lugares como Norte de África e noutras regiões da Europa Ocidental (Vigueira Molins, 2002; Teyssier 2001; Corriente, 2006).

Ainda assim, podem-se destacar três períodos diacrónicos, durante os quais se foi registando a integração dos arabismos na língua portuguesa, tal como consta na literatura sobre este tema. O primeiro período, que é o mais marcante, iniciou-se quando, em 711, Tārik (conhecido nas fontes pelo nome Tãrik Ibn Ziāde) atravessou o estreito de Gibraltar, 
pondo fim ao domínio dos reis visigodos. Três anos volvidos, os muçulmanos já dominavam a Península Ibérica. Naquele período, a integração dos arabismos nas línguas romances peninsulares, línguas faladas no Al-Andalus, correspondeu, sobretudo, à necessidade de definir objetos, profissões e técnicas que foram introduzidos em diversos domínios do conhecimento, durante a presença árabe e muçulmana, nas regiões chamadas Al-Andalus e Gharb Al-Andalus. Esta última região foi uma antiga província de Al-Andalus que correspondia a algumas regiões do Sul e do Centro de Portugal (Lisboa, Sintra, Almada, Évora, Santarém, Mértola e Alcácer do Sal) antes da Reconquista, onde as povoações sofreram uma arabização (Farinha, 1973; Vargens, 2007; Alves, 2013). A chegada dos falantes de árabe foi sendo feita de forma gradual e estes provinham de diferentes partes do mundo árabe, trazendo consigo a língua árabe clássica, juntamente com os dialetos falados por diferentes tribos - berberes, sírios, iemenitas, palestinos, egípcios, entre outros (Zayed, 1993). Com o estabelecimento do Califado, assistiu-se a um novo influxo de falantes árabes graças ao grande apoio que a corte dava às ciências e às artes.

De acordo com Corriente (1996), a arabização linguística e cultural dos hispano-godos cristãos era facilitada pelo prestígio que possuía a cultura arábico-islâmica naquela época, proporcionando a existência de uma sociedade bilingue:

\begin{abstract}
(...) a ocupação islâmica de Al-Andalus fez surgir logo uma sociedade, embora gradualmente, bilingue, com tendência para perda do romance, e islamizada, com uma tendência ainda mais rápida para desaparecimento do cristianismo e do judaísmo (Corriente, 1996, p. 4). ${ }^{4}$
\end{abstract}

\author{
4 Tradução nossa. "(...) la ocupación \\ islámica supuso en Alandalús la aparición \\ de una sociedad pronto aunque \\ gradualmente bilingüe con una tendencia \\ a la pérdida del romance, e islamizada \\ con una tendencia aún más rápida a la \\ desaparición de cristianismo y judaísmo."
}

Como resultado da intensa convivência entre hispano-godos e muçulmanos e do consequente processo de aculturação das populações nativas nas regiões do Al-Andalus e Gharb Al-Andalus, verificaram-se as primeiras influências linguísticas do árabe nos romances e nas línguas ibéricas, que se manifestaram de várias formas, algumas delas, como veremos mais adiante, híbridas.

O segundo período decorreu entre finais do século VIII e o século XIII (cf. Ribeiro, 1987; Corriente, 2003; Maranhão, 2018). As comunidades moçárabes continuaram a ser o principal veículo de transmissão deste património linguístico, mesmo para além do fim do domínio árabe e muçulmano na Península Ibérica. O termo moçárabe deriva do árabe 
musta'rib, cujo significado é "arabizado" (Corriente, 2003, s.v. moçárabe). Os chamados moçárabes constituíam uma grande comunidade que, para além de dominarem o idioma árabe, conservavam os seus idiomas românicos tradicionais, em situações informais ou domésticas, possibilitando a conservação de muitos nomes de origem árabe, tal como explica Azevedo:

Estas comunidades [moçárabe] falavam, na sua maioria, os idiomas românicos tradicionais e, simultaneamente, o árabe - a língua do poder e da administração. Esta situação de bilinguismo e diglossia coexistência e utilização de duas línguas em situações linguísticas e comunicativas funcionalmente diferenciadas - possibilitou, por um lado, a permanência de numerosos moçarabismos e, por outro, a entrada e a fixação de arabismos (Azevedo, 2015, p. 5). ${ }^{\mathbf{5}}$

Poder-se-á dizer, em parte, que estas influências se manifestavam na vida quotidiana medieval, entre os séculos IX e XIV, e podiam ser encontradas, nos domínios, por exemplo, da administração e da economia, bem como em determinadas profissões e ocupações, nomeadamente em postos militares e civis, em impostos, pesos e medidas. Estes indícios aparecem igualmente nas artes e ofícios e nas ciências, nestas com especial incidência nas ciências naturais, cultivadas e desenvolvidas pelos árabes e muçulmanos.

O terceiro período remete-nos à expansão ultramarina portuguesa. Quando esta atingiu o seu auge, novos contactos aconteceram nas praças portuguesas (Arzila, Safim, Azamor, Mazagão, entre outras), em Marrocos, entre o século XV e XVIII. Neste período e em todos estes lugares de influência árabe e muçulmana, a língua portuguesa absorveu uma grande quantidade de empréstimos lexicais, ampliando e complementando o anterior léxico de origem árabe (cf. Teyssier, 2001; Viguera Molins, 2002; Sidarus, 2009).

Em síntese, pode afirmar-se que o domínio árabe do território ibérico e o consequente prestígio da cultura arábico-islâmica na região foi fator primordial de transmissão de numerosas palavras de origem árabe aos então romances peninsulares. Esta influência foi alargada noutros períodos temporais por via do contacto como, por exemplo, com as populações do Norte de África. A entrada de palavras árabes no léxico português ocorreu, também, de forma indireta, pela introdução de palavras com origem noutras línguas europeias, principalmente no italiano e no francês (Vargens, 2007). 
Como mencionado anteriormente, os investigadores indicam uma periodização relativa à entrada dos arabismos na língua portuguesa; porém, o mesmo já não se verifica em relação à quantidade de itens lexicais importados da língua árabe, conforme se exemplifica na tabela seguinte:

\begin{tabular}{l|c|l}
\multicolumn{1}{c|}{ Autores } & $\begin{array}{c}\text { Arabismos } \\
\text { contabilizados }\end{array}$ & \multicolumn{1}{c}{ Fontes } \\
Nascentes (1966) & 609 & Dicionário Etimológico da Língua Portuguesa \\
Ribeiro (1987) & 600 & A formação de Portugal \\
Franca (1994) & 1000 & Arabismos: uma minienciclopédia do mundo árabe \\
Machado (1997) & 4000 & Influência arábica no vocabulário português \\
Vargens (1999) & 3000 & Arabismos na língua portuguesa (subsídios para \\
& 1000 & um estudo do léxico português de origem árabe) \\
Teyssier (2001) & História da língua portuguesa
\end{tabular}

Quadro 1. Exemplos de dados quantitativos sobre os arabismos no português.

Pela análise da tabela, podemos inferir que a discordâncias acerca do número exato dos arabismos no português terá origem nos diferentes critérios utilizados pelos investigadores na recolha dos dados. Por um lado, e adotando uma perspetiva mais ampla, alguns investigadores (cf. Machado, 1997; Vargens, 1999) levam em consideração arabismos que apresentam formas derivadas (p. ex. azeite, azeitona, Algarve, algarvio, alfaiate, alfaiataria), ao passo que outros apenas reconhecem as formas simples (sem sufixos nem prefixos) e o léxico mais conhecido, não incluindo na sua análise os vocábulos arcaicos que se encontram em desuso.

\section{Opções metodológicas do estudo empírico: a recolha dos dados}

Conforme foi referido, o legado linguístico árabe é notório na língua portuguesa e surgiu em determinadas épocas históricas para preencher um vazio linguístico relacionado com uma nova técnica ou um conceito desconhecido pelos habitantes do Gharb Al-Andalus, constituindo assim um campo vasto, impossível de ser analisado na sua globalidade. Pelas características desta publicação, foram selecionados vinte (20) itens lexicais, compilados e validados cientificamente, por especialistas (cf. Farinha, 1973; Machado, 1997; Vargens, 1999), como arabismos pertencentes a várias categorias semânticas (técnicas e produtos agrícolas; 
guerra e vida militar; indústria e comércio; administração e finanças; profissões; ciências, técnicas e artes; pesos e medidas, etc.), evidenciando, de certa forma, os domínios mais marcantes do contacto entre os árabes e os habitantes da Península Ibérica.

Como dissemos na introdução, através desta recolha seletiva pretendeu-se identificar e analisar alguns aspetos que caracterizam os arabismos na língua portuguesa, nomeadamente através da presença ou não do artigo solar ou lunar e das alterações fonéticas. Apresentaremos os arabismos em análise, referindo o campo semântico e a sua correspondência na língua árabe, apoiada pela transliteração. Para a explicação do significado dos arabismos, socorrer-nos-emos das definições comuns presentes em dois dicionários de uso alargado no meio académico, Infopédia (Porto Editora) e Houaiss. Para além destas duas referências, utilizaremos como fonte o texto de Fr. João de Sousa ([1789]; 2004) por forma a contextualizar historicamente o significado de um determinado arabismo. Optámos por esta abordagem triangular, que combina dois ou mais pontos de vista, fontes de dados, abordagens teóricas ou métodos de recolha de dados numa mesma investigação, porque nos pareceu ser aquela que permitia alcançar conclusões mais fidedignas sobre a compreensão do tema em análise (Denzin \& Lincoln, 2000; Coutinho, 2012), ou seja, a influência do árabe na língua portuguesa.

\section{Apresentação da análise dos dados}

Antes de iniciar a análise, por forma a facilitar a compreensão de alguns aspetos da análise dos dados, importa explicar algumas especificidades da língua árabe relacionadas com o artigo. Assim, no árabe encontramos o artigo definido, nas suas duas formas, a lunar e a solar, pronunciados respetivamente [al] e [a] e ambos escritos ligados às palavras que definem. Por força do artigo mencionado, as consoantes do alfabeto árabe são divididas, também, em lunares e solares. Note-se que esta diferença nos artigos é puramente fonética, refletindo-se apenas na oralidade e não na grafia. Ambos os artigos são escritos com [al / IJ]; no artigo lunar são pronunciados [a: alife / I] e [l: lame / J]; no artigo solar o [l: lame / J] é omitido na oralidade. Para exemplificar o que acaba de ser descrito, veja-se o caso da palavra "azeite", que em árabe é escrita alzeite e se pronuncia azzaite, uma vez que o [z] é uma consoante solar. As regras de leitura obrigam, neste caso, à omissão do [l] e a que o fonema representado pelo grafema [z] seja pronunciado enfaticamente, com movimento (haraka), levando chadda. ${ }^{6}$

6 Em árabe, a chadda é um traço ortográfico que se coloca sobre as consoantes e cuja função é enfatizar a pronúncia das mesmas. 
Refira-se que, ao contrário do que acontece no português, o artigo definido (lunar e solar), na língua árabe, apresenta uma forma gramatical simples, não concordando nem em género nem em número.

Importa sublinhar que o corpus selecionado engloba arabismos da agricultura (acéquia, açúcar, açude, alface, alfarroba, alfazema, azeite e tâmara), administração e exército (adail, alcaide, alfaqueque, alferes, almoxarife e refém), música e decoração (adufe, alaúde e jarra) e medidas (almude). Estes vocábulos serão apresentados e analisados por ordem alfabética. Por último, no que diz respeito à transliteração, optamos por deixar aglutinados os artigos [al] e [a] aos substantivos, respeitando, neste caso, as regras morfológicas da língua árabe (vide os exemplos apresentados em árabe).

\section{Agricultura}

Acéquia [Técnica agrícola, do árabe assāqiyah / الساقية] um canal estreito artificial para as águas correntes. Esta palavra, que se integrou com o artigo solar [a], é pronunciada na língua portuguesa da mesma forma que no árabe assāqiyah. Conservou o género feminino da língua árabe. Ao ser absorvida pela língua portuguesa, perdeu o morfema gramatical deste género [ta / : - marbouta].

Açúcar [Produtos agrícolas, do árabe assukkar / السكر]: substância doce extraída de várias plantas, especialmente a cana-sacarina e a beterraba, composta essencialmente por sacarose e usada como adoçante. Trata-se de um substantivo masculino, que apresenta o artigo solar [a]. Nesta palavra, verifica-se a conservação do género masculino, bem como a pronunciação da língua árabe.

Açude [Técnica agrícola, do árabe assad / السد ]: indica uma construção feita num curso de água, destinada a ter ou derivar para abastecimento, irrigação, produção de energia. Conservou o artigo lunar e o género masculino no português. Este vocábulo pronuncia-se de forma similar na língua árabe, apresentando, apenas, uma ligeira alteração na segunda sílaba. Os muçulmanos falantes de árabe introduziram esta técnica de regadio para controlar o consumo sustentável da água. Apesar do uso das novas tecnologias, a ideia da sustentabilidade do uso da água implementada pela construção do açude não foi abandonada. Na língua de partida, o significado desta palavra tem um uso mais amplo, podendo representar uma grande ou pequena barragem, bem como indicar a ideia de superar um obstáculo ou dificuldade. 
Alface [Produtos agrícolas, do árabe alkhass /الخس]]: planta herbácea comestível, da família das Compostas, muito cultivada nos países do mediterrâneo, cujas folhas, bem como as de outras variedades da mesma espécie, são muito utilizadas na culinária, sobretudo na preparação de saladas. Na oralidade, esta palavra conserva parcialmente a pronúncia da língua árabe apenas com uma ligeira alteração fonética no grafema [f] que é, em árabe, um fonema representado pelo grafema [j] pronunciado como no espanhol. Em relação ao género, a palavra alface, no português é um substantivo feminino (singular), enquanto em árabe aparece nos dicionários como substantivo masculino (plural).

Alfarroba [Produtos agrícolas, do árabe alkharrūb / الخروب ]: trata-se de um fruto adocicado da alfarrobeira. É um substantivo feminino, não tendo conservado o género masculino que apresenta na língua árabe, ainda que tenha mantido, tal como em árabe, o artigo lunar [al]. Todas estas descrições se aplicam, também, à palavra Alfarrobeira. Existe no Sul de Portugal (Algarve e Alentejo) uma agricultura sustentável de alfarroba que se reflete na tradição culinária desta região. Esta palavra conserva parcialmente a pronúncia da língua árabe, com ligeiras alterações, tal como acontece na palavra alface.

Alfazema [Produtos agrícolas, do árabe alkhuzāma / الخزامى]: é uma espécie de plantas do género lavandula, da família das labiadas geralmente cultivadas como ornamentais e pelas suas características aromáticas. Integrou-se com as características gramaticais da língua árabe, conservando o género feminino e o artigo lunar [al]. Pode dizer-se que este léxico conserva parcialmente a pronúncia da língua (vide alface, alfarroba, alfarrobeira).

Azeite [Produtos agrícolas; do árabe azzait / الزيت] : gramaticalmente, o vocábulo conserva o género masculino da língua árabe e foi integrado com o artigo solar [a], omitindo o grafema [I]. Este arabismo entrou no português mantendo a sua pronúncia original (embora dele conste o [I] que pelas razões já explanadas não se pronuncia). Este raciocínio é igualmente aplicável à palavra.

Azeitona [do árabe azzaitūna / الزيتونة]: fruto drupáceo, produzido pela oliveira, que fornece o azeite. Em árabe o vocábulo azeitona corresponde a um substantivo singular. Conserva no português o género feminino da língua árabe, embora registe uma omissão do morfema gramatical do feminino (ta/ $\ddot{a}$ - marbouta), que aparece sempre no fim das palavras deste género. Contudo, importa salientar que o plural deste vocábulo, em árabe, é masculino [ azzaitūn / الزيتون]. 
Tâmara [Produtos agrícolas, do árabe Tamr / تصَ]: fruto da tamareira, apreciado depois de seco e preparado. Ao contrário da maioria dos arabismos, este arabismo integrou-se no português sem o artigo solar [a]. Trata-se de um substantivo feminino, não tendo conservado o género masculino que apresenta na língua árabe. O singular desta palavra em árabe [Tamra / تمرة] é pronunciada relativamente do mesmo modo que "tâmara" em português. Na tradição árabe e muçulmana, baseada nos ditos e nos atos do Profeta Maomé [Muhammad], a tâmara é um fruto que é consumido pelos muçulmanos, sobretudo no Ramadão (4० pilar do Islão), período durante o qual se jejua do nascer do sol até ao pôr do sol.

\section{Administração e Exército}

Adail [Profissões, do árabe addalil / الدليل ]: deriva do verbo dalla que significa ensinar, mostrar o caminho, guiando ou apontando o dedo. A função do adail era mostrar e ensinar o caminho, quando o exército marchava. No processo de integração deste arabismo no português, regista-se a permanência do artigo solar [a] e a omissão da letra [I], tal como se pode constatar na transliteração. No que diz respeito ao significado, este arabismo continua a significar, genericamente, um guia que fornece informações sobre um assunto determinado.

Alcaide [Guerra e vida militar, do árabe alqāid / القائد ]: aquele que governava um castelo, província e/ou comarca com poder civil ou militar; antigo governador. Atualmente, em Espanha, refere-se ao indivíduo responsável pela administração cujas funções são semelhantes às de presidente da câmara, em Portugal. Integrou-se na língua portuguesa com o artigo lunar [al] e manteve o género masculino do árabe. A sua pronúncia, em português, é relativamente próxima à que existe em árabe. Contudo, o seu significado atual na língua árabe é muito amplo, isto é, engloba todas as funções que implicam liderança em todos os domínios.

Alfaqueque [Guerra e vida militar, do árabe alfakkāk / الفكالك)]: redentor de cativos; o que tratava com os "mouros" o resgate de prisioneiros; emissário para resolver conflitos entre "mouros" e cristãos. O alfaqueque devia ter algumas qualidades essenciais: ser sincero, não ser ganancioso, conhecer fluentemente as línguas, não ser hostil, ser corajoso e ter propriedades. O substantivo alfaqueque deriva do verbo fakka, soltar e resgatar no sentido de dar liberdade. Embora se considere um arabismo arcaico, isto é, de conhecimento e uso não comuns, a sua entrada na língua portuguesa permaneceu intacta, em todos os aspetos gramaticais (artigo, género, pronúncia). Fora do contexto histórico, este termo em 
árabe contemporâneo continua a significar uma pessoa que é capaz de resolver um problema de toda a índole.

Alferes [Guerra e vida militar, do árabe do árabe alfāris / الفارس]: antigo posto militar, equivalente ao atual de segundo-tenente; militar que detém esse posto. Responsável por carregar a bandeira de um regimento militar (porta-bandeira). Conserva o artigo lunar [al] e a pronúncia da língua árabe. No que respeita ao significado, atualmente a palavra alferes em árabe tem um sentido mais restrito, referindo-se a um cavaleiro que monta o cavalo na prática desportiva do hipismo.

Almoxarife [Administração e finanças; do árabe almuxrif / لمشرف]: quem se responsabiliza pelo almoxarifado, pelo depósito de materiais e matérias-primas de uma empresa. Pessoa responsável por cobrar as rendas reais; tesoureiro que exercia o seu ofício na casa real. Pode deduzir-se que não houve grande alteração no que respeita à pronúncia do português em comparação com a língua árabe. A semelhança com o árabe, verifica-se também na integração deste arabismo com o artigo lunar [al] e ao nível do género permanece masculino.

Almotacé [Administração e finanças, do árabe almohtacib / المحتسب]:antigo inspetor camarário de pesos e medidas que fixava o preço dos géneros alimentícios. Este arabismo deriva do verbo haçaba cujo significado é contar, calcular, reputar, taxar o preço de qualquer coisa pertencente. $\mathrm{O}$ termo parece ter perdido, aquando da sua integração no português, dois sons originais da língua árabe, representados pelos grafemas [ح] e [ب], mas manteve o artigo lunar [al] e o género masculino do árabe.

Refém [Guerra e vida militar, do árabe rahn /رهن]: significa a pessoa ou povoação que fica em poder do inimigo como garantia da execução ou cumprimento de um acordo ou tratado; pessoa que é aprisionada e mantida como garantia até as exigências do raptor serem satisfeitas. Este arabismo foi integrado no português sem artigo, neste caso concreto, 0 solar [a]. Nota-se ainda na palavra refém uma ligeira diferença ao nível da pronúncia em relação à do árabe [rahn], sobretudo no que toca ao grafema [॰-] do árabe que se transforma em [f] no português. A palavra refém manteve o género masculino na língua árabe. 
Adufe [Ciências e artes, do árabe adduf/الداف]: pandeiro quadrado, com peles retesadas dos dois lados e cosidas entre si, dentro do qual são colocadas sementes, grãos ou soalhas, por forma a enriquecer a sonoridade. Trata-se de um arabismo que, ao entrar no português com o artigo solar [a], conservou totalmente todas as características gramaticais e fonéticas na língua portuguesa. É um instrumento que continua a ser utilizado na música popular em todos os países árabes e na música tradicional da Beira Baixa.

Alaúde [Ciências e artes, do árabe al'aud / العود / instrumento musical em forma de meia pera, de origem árabe, com cravelhas situadas no braço em ângulo reto, usado na Europa nos séculos XVI e XVII. Ao ser integrado na língua portuguesa, a palavra alaúde conservou algumas características da língua árabe, tais como o género masculino e o artigo lunar. Ao nível da pronúncia, registou-se uma pequena alteração fonética uma vez que o fonema $[\varepsilon]$ não encontra correspondência na língua portuguesa. Este instrumento continua a ser uma referência importante na música árabe.

Jarra [Ciências e artes, do árabe jarrah / الجرة ]: recipiente onde se colocam flores ou que é utilizado como peça ornamental; recipiente mais ou menos bojudo, alto, com asa e bico, para servir água ou vinho; jarro. Como se pode observar, é um dos arabismos que entraram na língua portuguesa sem o artigo, neste caso, o lunar, contudo, conservou o género feminino e a pronúncia tal como no árabe. Também se regista a omissão do morfema gramatical [ta / ò marbouta].

\section{Medidas}

Almude [Pesos e medidas, do árabe almudd / المد]: antiga unidade de medida de capacidade equivalente a 12 canadas ou 48 quartilhos; medida de 25 litros, no sistema métrico decimal; medida que atualmente em Portugal varia de 16,5 a 40 litros, conforme as regiões. No árabe almudd era usado como medida de grãos. Hoje em dia, é uma medida de peso que se usa para medir trigo ou outros cereais para dar de esmola e oferta aos necessitados no fim do Ramadão (Aid al fitr / festa da esmola). Um almude corresponde mais ou menos a $0,65 \mathrm{~kg}$. Na sua integração na língua portuguesa, para além da pronúncia, conservou o género masculino e o artigo lunar [al]. 
Finalizada esta exposição, ficou patente que os arabismos apresentam várias influências morfológicas na língua portuguesa. No aspeto linguístico, demostrámos que os arabismos do português conservam algumas características da língua de partida, tais como a conservação do artigo lunar (ex. alface, alfazema, almoxarife) e solar (ex. adufe, açude, açúcar) que são aglutinados aos substantivos. Para além destes, assistiu-se à integração doutro tipo de arabismos - sem o artigo lunar [al] nem o solar [a] (ex. jarra, refém).

Importa ainda notar que o processo de integração dos arabismos no português apresenta algumas adaptações fonéticas, através da alteração e/ou omissão de alguns sons. Este processo resultou de uma necessidade linguística, uma vez que o árabe tem sons que não encontram correspondência no sistema fonético português, tornando, assim, impossível a sua transliteração exata para este idioma. Isto aplica-se a alguns dos arabismos analisados, como alface, alfarroba e alfazema. Na língua de partida, o árabe, o grafema [f] é representado pela letra árabe [خ்], pronunciado como o [j] em espanhol. O mesmo se pode dizer em relação ao arabismo alaúde onde, em árabe, figura, na sua segunda sílaba, a letra [ع], cujo som não tem equivalente no português. Consequentemente, o som que representa a letra $[\varepsilon]$ acaba por ser omitido e não ser representado por nenhum grafema. Esta omissão ocorre, também, na palavra almotacé (do árabe almohtacib), sendo omitido o som que corresponde ao grafema [₹].

Existem outros arabismos que, no seu processo de aproximação à língua portuguesa, continuam a pronunciar-se da mesma forma que no árabe (ex. açúcar, azeite, azeitona, adufe, almude) ou de forma próxima (ex. alfaqueque, alferes, acéquia, açude). Esta transparência linguística facilita a aprendizagem destes vocábulos pelos alunos de árabe e português como línguas estrangeiras, tal como acontece nas línguas românicas próximas.

É inegável que o contacto entre estas duas línguas e a introdução de um número considerável de arabismos na língua portuguesa constitui uma faceta da interação cultural dos seus falantes e da integração de diversos aspetos da cultura árabe no espaço sociocultural de Portugal, que se mantêm, em alguns casos, até ao presente. Isto é patente em diversos domínios desde o uso dos instrumentos de música (ex. adufe, alaúde) e elementos de decoração (ex. jarra) até à culinária. Em algumas regiões 
do Sul de Portugal, a alfarroba é muito utilizada na preparação de uma variedade de pão e doces. Através dos arabismos, deram-se a conhecer algumas profissões relacionadas com a área militar (ex. alcaide, adail, almoxarife, alferes), área lexical que reflete a realidade menos pacífica de que também se revestiu a história dessa relação. Muitos destes arabismos, embora não de uso comum, (ex. adail, alcaide, alfaqueque. almoxarife, alcaide) são usados como elementos de verosimilhança nos romances históricos de Alexandre Herculano ou no teatro de Gil Vicente (cf. Suisse, 2004).

\section{Considerações finais}

As contribuições importantes do léxico árabe na língua portuguesa prendem-se, sobretudo, com a inclusão de vocabulário inexistente no português para definir saberes, costumes, objetos e técnicas que eram introduzidos na sociedade da população cristã por via dos muçulmanos. Com este artigo, procurou-se estudar alguns arabismos que incorporam a língua portuguesa, destacando, particularmente, os aspetos linguísticos e culturais.

Assim, após evocar alguns períodos históricos que marcaram a entrada dos arabismos na língua portuguesa, passámos a identificar, com base da análise contrastiva, marcas de influência interlinguística presentes num corpus selecionado de palavras referentes a vários campos semânticos. Esta seleção permitiu-nos mostrar, por um lado, os domínios e as áreas mais importantes do contacto entre cristãos e muçulmanos na Península Ibérica e, por outro, traços de influência linguística. Estes traços, caracterizando a língua do Outro, contribuíram, inegavelmente, para o enriquecimento lexical do português e refletiram-se, por exemplo, na conservação do artigo aglutinado aos substantivos, bem como nas adaptações fonológicas e possíveis alterações e no significado. A este respeito, foi importante identificar e explicar a adaptação fonética devido às diferenças naturais entre as línguas em contacto - o português e o árabe que se verifica em casoso como os dos vocábulos alface, alfarroba e alfazema.

Nestes substantivos, os aprendentes, dominando a língua de partida, acabam por usar uma forma híbrida na constituição das palavras, empregando os dois artigos - do português [o] e do árabe [al] ou [a]. Na nossa opinião, a presença dupla do artigo afigura-se como o traço mais marcante dos arabismos na língua portuguesa, constituindo um dos contributos científicos que aporta este artigo. 
No que se refere ao significado, referimos que algumas palavras de origem árabe aquando da sua integração na língua portuguesa serviram para designar várias realidades e significados, tendo em conta o contexto histórico.

Por fim, acreditamos que o estudo dos arabismos numa perspetiva interdisciplinar - na qual os contextos históricos fundamentem a explicação dos fenómenos linguísticos - poderá contribuir para relatar muitos aspetos da coexistência entre cristãos e muçulmanos, alicerçada na tolerância religiosa e respeito pelas leis e costumes de cada povo, como, de resto, foi testemunhado por vários documentos históricos e que, seguramente, será corroborado por outros que ainda estarão por descobrir e estudar.

\section{Bibliografia}

Alves, A. (2013). Dicionário de Arabismos da Língua Portuguesa. Lisboa: Imprensa Nacional-Casa da Moeda.

Azevedo, M. M. (2015). Moçarabismo e toponímia em Portugal. Lisboa: Academia das Ciências de Lisboa.

Corriente, F. (1996). "Novedades en el estudio de los arabismos en iberorromance". Revista Española de Lingüística, 26, 1, 1-13.

- (2003). Diccionario de arabismos y voces afines en iberorromance. Madrid: Gredos.

- (2006) "Romania Arabica: uma questão não resolvida de interferência cultural na Europa Ocidental". Signum, 8, 81-91.

Coutinho, C. P. (2012). Metodologias de investigação em Ciência Sociais e Humanas: Teoria e Prática. Coimbra: Almedina.

Dictionnaire de Français Larousse. Disponivel em: https://www.larousse.fr/ dictionnaires/francais.

Diccionario de la lengua española [em linha]. Real Academia Española (RAE). Disponível em: https://dle.rae.es/ diccionario.

Dicionário infopédia da Língua Portuguesa [em linha]. Porto: Porto Editora, 20032020. Disponivel em: https://www. infopedia.pt/dicionarios/lingua-portuguesa
Denzin, N. K. e Lincoln, Y. S. (2000). "Introduction: The discipline and practice of qualitative research". In N. K. Denzin, \& Y. S. Lincoln (Eds.), Handbook of qualitative research (pp. 1-28). California: Sage Publications, Thousand Oaks.

Farinha, A. D. (1973). "Contribuição para o estudo das palavras portuguesas derivadas do árabe hispânico" Portugaliae Historica VI. Lisboa: Faculdade de Letras da Universidade de Lisboa, Instituto Histórico Infante Dom Henrique, pp. 244-265.

Franca, R (1994). Arabismos: uma minienciclopédia do mundo árabe. Recife: Prefeitura da Cidade do Recife: EDUFPE.

Houaiss, Dicionário de Português [em linha]. Disponível em: https://www.dicio.com.br/ houaiss/

Lopes, D. (1940). Textos em aljamía portuguesa: documentos para a história do domínio português em Safim (extrahidos dos originaes da Torre do Tombo (1897). Lisboa: Imprensa nacional.

Machado Filho. L. (2013). "Arabismos e germanismos em textos medievais portugueses". In Encontro Internacional dos Estudos Medievais - ABREM 10 (pp. 392-400). Brasília: Editora Universidade de Brasília.

Machado, J. P. (1997). Vocabulário português de origem árabe. Lisboa: Editorial Notícias. 
Maranhão, S. M. (2018). "Arabismos portugueses no contexto multilinguístico da Península Ibérica Medieval" Caligrama, $23,2,121-143$

Nascentes, A. (1966). Dicionário etimológico resumido. Rio de Janeiro: Instituto Nacional do Livro. Ministério da Educação e Cultura.

Ribeiro, O. (1987). A formação de Portugal. Lisboa: Instituto de Cultura e Língua Portuguesa.

Sidarus, A. (1986). "Os estudos árabes em Portugal". In Islão e Arabismo em Terra Lusitana (pp. 392-400). Évora: Publicações da Universidade de Évora.

- (2009). Arabismos e traduções árabes em meios luso-moçárabes. Covilhã: Luso Sofia-Press.

Silva, N. S. (1992). História da língua portuguesa. Lisboa: Dinalivro.

Sousa, F. J. ([1789] 2004). Vestígios da Língua Arábica em Portugal. Lisboa: Alcalá.

Suisse, A. (2004). "A Imagem dos Árabes na Literatura Portuguesa: os exemplos de Gil Vicente e Alexandre Herculano". In Portugal, Espanha e Marrocos: o Mediterrâneo e o Atlântico. Centro de Culturas Árabes, Islâmicas e Mediterrânea (pp. 70-75). Faro: Faculdade de Ciências Humanas e Sociais da Universidade do Algarve,
Teixeira, M. (2009). "Os estrangeirismos no léxico português - uma perspectiva diacrónica" Filologia linguística portuguesa, 10/11, 81-100. Disponível em http://www.fflch. usp.br/dlcv/lport/flp/images/arquivos/FLP1O11/Teixeira.pdf

Teyssier, P. (1980). História da língua portuguesa. Lisboa: Sá da Costa Editora.

Vasconcelos, C. M. de (1946). Lições de filologia portuguesa. Lisboa: Revista de Portugal.

Vargens, J. B. (1999). Arabismos na língua portuguesa (subsídios para um estudo do léxico português de origem árabe). Tese Doutoramento. Lisboa: FLUL.

- (2007). Léxico português de origem árabe: subsídios para os estudos de filologia. Rio Bonito: Almádena.

Viguera Molins, M. J. (2002). Lengua árabe y lenguas románicas. Revista de Filología Románica, 19, 15-54.

Zayed, A. M (1993). Datos dialectales andalusies (gramaticales y léxicos) en algunos documentos tardíos granadinos $y$ moriscos. Tese de Doutoramento. Madrid: Universidad Complutense, Facultad de Filología. Departamento de Estudios Árabes e Islámicos. Disponível em: http://eprints.ucm. es/tesis/19911996/H/3/AH3030101.pdf 